\title{
Multistage closure of a congenital extrahepatic portosystemic shunt
}

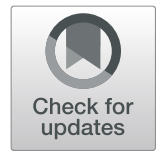

João Facas ${ }^{1 *}$ (D), Manuel Cruz ${ }^{1}$, João Filipe Costa ${ }^{1}$, Alfredo Agostinho ${ }^{1}$ and Paulo Donato ${ }^{1,2}$

\begin{abstract}
Background: Congenital extrahepatic portosystemic shunts (CEPS) are rare shunts connecting the extrahepatic portal system with the inferior vena cava. Shunt dimensions and the risk of portal hypertension determines the closure strategy. Endovascular treatment is indicated for single stage occlusion of longer length shunts, whereas the remaining shunt types are preferentially surgically occluded. Herein we describe the technical details of a novel endovascular treatment for short length CEPS.

Case presentation: A 15-years-old male with a short length CEPS complicated with multinodular liver disease was submitted to a multistage closure, as indicated by the high portal pressure values during shunt balloon occlusion venography. Initially a transjugular intrahepatic portosystemic shunt (TIPS) was created and the CEPS occluded with an atrial septal defect occluder. In a second procedure the TIPS was embolized with a flow reductor stent and an amplatzer vascular plug II. At a 1 year follow up the liver nodules size reduced, the patient remains asymptomatic, and the shunt adequately closed.
\end{abstract}

Conclusion: This paper outlines the potential use of a TIPS and an atrial septal defect occluder combination in complex CEPS, supporting its usage as an alternative to the standard surgical treatment.

Level of Evidence: Level 4, Case report.

Keywords: Congenital extrahepatic portosystemic shunt, Abernethy, Atrial septal defect occluder, Transjugular intrahepatic portosystemic shunt, Balloon occlusion venography

\section{Background}

Congenital extrahepatic portosystemic shunts (CEPS), also known as Abernethy malformations, are rare shunts connecting the portal system proximal to its bifurcation with the supra-renal inferior vena cava (IVC) (AlonsoGamarra et al., 2011). CEPS are further divided into type I, an end-to-side shunt without intrahepatic portal system, and type II, a side-to-side shunt with an underdeveloped intrahepatic portal system, where both surgical and endovascular closure is feasible (FranchiAbella et al., 2018).

The portal blood bypass results in a liver perfusion disarrangement and an impaired first pass effect,

\footnotetext{
* Correspondence: facasmartins@gmail.com

${ }^{1}$ Medical Imaging Department, Coimbra University Hospital, Praceta Prof. Mota Pinto, Coimbra, Portugal

Full list of author information is available at the end of the article
}

responsible for the clinical spectrum in untreated CEPS which includes nodular liver disease, hyperammonemia, encephalopathy and hepatopulmonary syndrome. When complications are present closure is recommended, as CEPS spontaneous closure is uncommon (Baiges et al., 2020; Rajeswaran et al., 2020).

Treatment selection is based on the risk of portal hypertension and shunt dimensions. A venography is performed, and the shunt temporarily occluded with a balloon to determine portal pressure before and after shunt occlusion. If portal pressure after shunt occlusion is above $24 \mathrm{mmHg}$ or portal pressure gradient before/ after shunt occlusion is above $9 \mathrm{mmHg}$ a multistage closure must be selected due to the increased risk of portal hypertension. As for shunt dimensions, it's a subjective classification where a shunt is considered short length when the risk of non-target embolization and
Springer Open (c) The Author(s). 2021 Open Access This article is licensed under a Creative Commons Attribution 4.0 International License, which permits use, sharing, adaptation, distribution and reproduction in any medium or format, as long as you give appropriate credit to the original author(s) and the source, provide a link to the Creative Commons licence, and indicate if changes were made. The images or other third party material in this article are included in the article's Creative Commons licence, unless indicated otherwise in a credit line to the material. If material is not included in the article's Creative Commons licence and your intended use is not permitted by statutory regulation or exceeds the permitted use, you will need to obtain permission directly from the copyright holder. To view a copy of this licence, visit http://creativecommons.org/licenses/by/4.0/. 
turbulent flow with standard coils or plugs precludes a safe procedure. Endovascular treatment is indicated for long length single stage closures, whereas short length shunts and multistage occlusions are preferentially surgically approached with ligation, clips placement, caval partition or banding, often in combination with endovascular treatment. (Baiges et al., 2020; Bruckheimer et al., 2013; Rajeswaran et al., 2020).

We report a multistage occlusion of a short length CEPS occluded with an atrial septal defect plug in combination with a transjugular intrahepatic portosystemic shunt (TIPS) creation, that was later occluded with a flow reductor stent and an amplatzer vascular plug II.

\section{Case presentation}

A 15-year-old male was referred to a gastroenterology consultation due to increased total bilirubin $(71,8 \mu \mathrm{mol} /$ $\mathrm{L})$, alanine transaminase $(65 \mathrm{IU} / \mathrm{L})$ and aspartate transaminase $(55 \mathrm{IU} / \mathrm{L})$ levels. Ammonia levels were normal. The lab tests were required before isotretinoin initiation for acne disease. The patient was asymptomatic and had no relevant past history.

An abdominal ultrasound identified multiple hyperechoic nodules and a direct communication between the portal trunk and the IVC with hypoplastic portal branches. Subsequent CT and MRI confirmed the presence of a type II CEPS, measuring $16 \mathrm{~mm}$ in diameter and $4 \mathrm{~mm}$ in length, and the nodules were characterized as probable regenerative nodules (Fig. 1).

The patient underwent a portocaval venography and shunt temporarily occluded with a balloon. Portal pressure values increased from $16 \mathrm{mmHg}$ to $28 \mathrm{mmHg}$ after occlusion (12 $\mathrm{mmHg}$ gradient). Given these values a progressive closure of the CEPS was planned.

In the initial procedure, through a transjugular access, a TIPS was created between the middle hepatic vein and right portal vein GORE $^{\circ}$ VIATORR $^{\circ}$ TIPS Endoprosthesis $8-10 \times 50+20 \mathrm{~mm})$. Using the 10F TIPS sheath the CEPS was occluded with a $16 \mathrm{~mm}$ atrial septal defect occluder (Amplatzer ${ }^{\text {Tix }}$ septal occluder, Abbott ${ }^{\circ}$ ), matching the CEPS diameter previously measured on CT. The TIPS was created before the CEPS occlusion to avoid the risks of an unsuccessful TIPS creation (Fig. 2A and B). TIPS patency and CEPS closure were assessed with Doppler ultrasound.

A second procedure was performed forty days later with downstaging of the TIPS caliber using a flow reductor stent $(14 / 4 / 14 \times 40 \mathrm{~mm}$ sinus-reduction stent, Optimed $^{\odot}$ ), resulting in a minor increase in portal pressure from 6 to $8 \mathrm{mmHg}$ (Fig. 2C). Temporary shunt balloon occlusion was repeated with portal pressure increasing to $14 \mathrm{mmHg}$. According to these portal pressure values a decision was made to definitively occlude the TIPS using a $14 \mathrm{~mm}$ Amplatzer ${ }^{\mathrm{rm}}$ Vascular Plug II (Fig. 2D). The patient was started on $40 \mathrm{mg} /$ day of enoxaparin.

Likewise, TIPS and CEPS closure were accessed with Doppler ultrasound. At 2 weeks follow up a nonocclusive peripheral thrombus was identified in the left portal branch and enoxaparin dosage upscaled to $60 \mathrm{mg} /$ day. The thrombus resolved 3 months later and enoxaparin was withdrawn. At a 1 year follow up the TIPS and

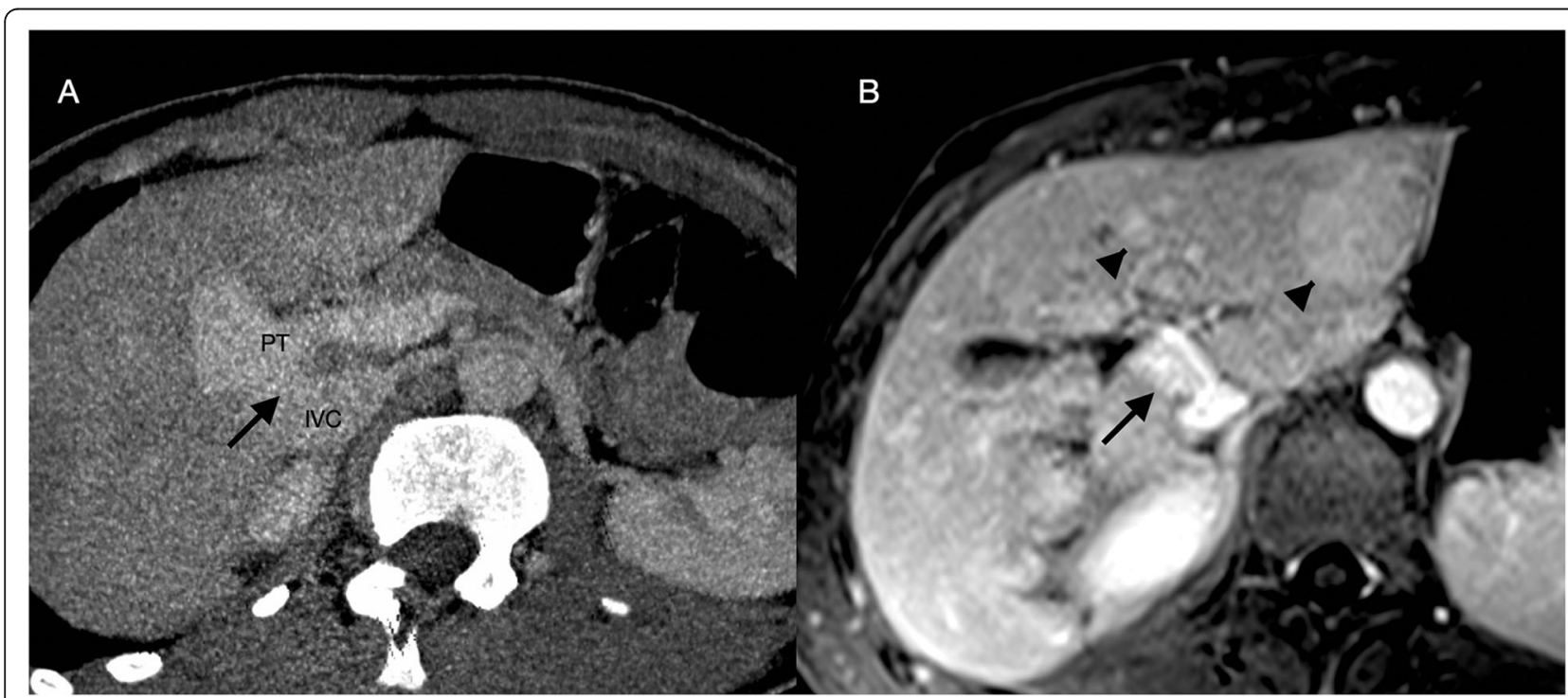

Fig. 1 Type II congenital extrahepatic portosystemic shunt. A) CT mutiplanar reconstruction. A wide and short length shunt (black arrow) is seen connecting the inferior vena cava (IVC) and the portal trunk (PT). B) Axial equilibrium phase T1-weighted MR image with gadobutrol shows two slightly hyperintense nodules. These were also hyperintense on arterial and portal phases, compatible with the diagnosis of regenerative nodules (arrow heads) 


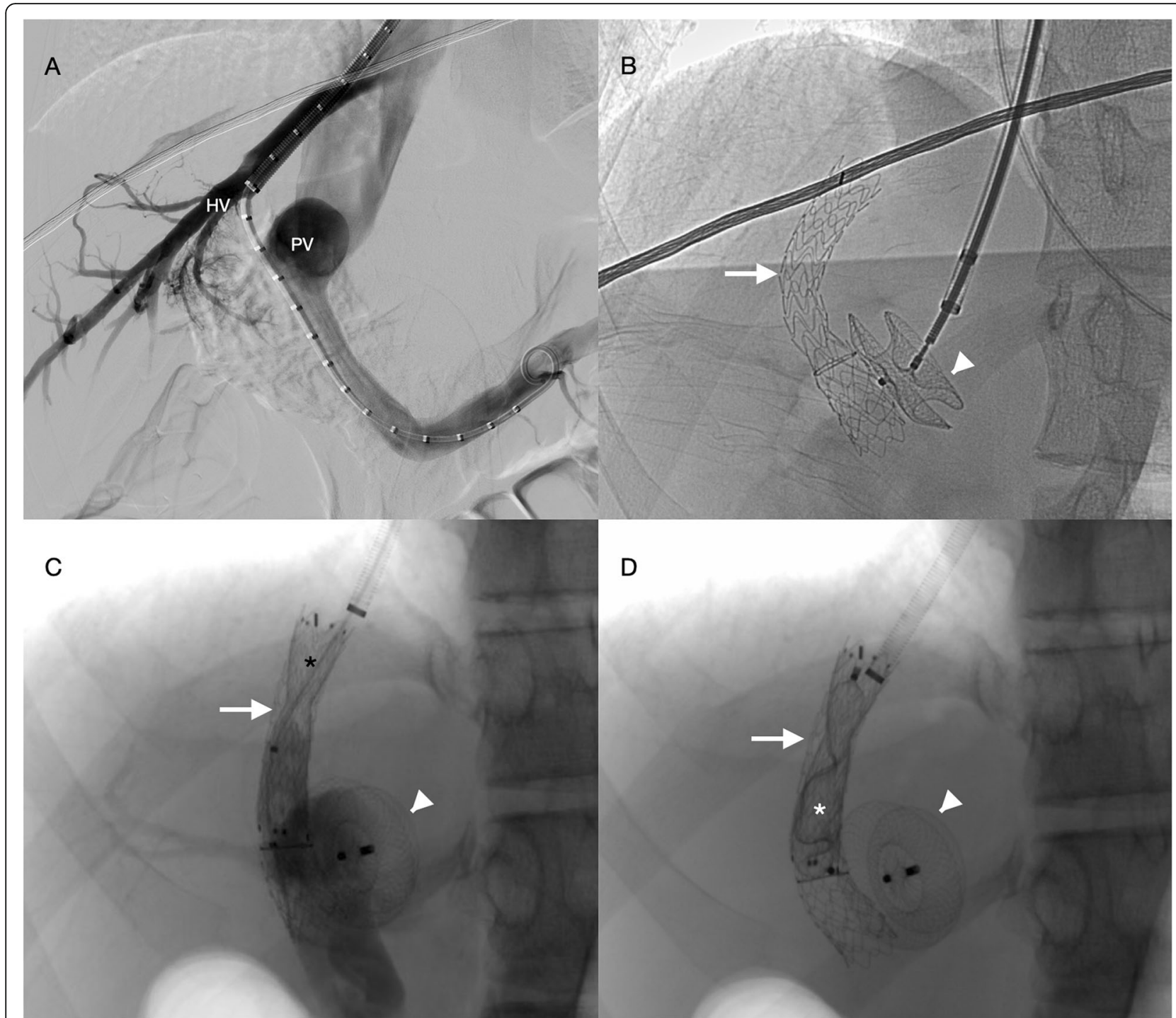

Fig. 2 Multistage closure of a type II congenital extrahepatic portosystemic shunt. A) and B) In the first procedure an atrial septal defect plug (white arrowhead) was deployed in the shunt after a transjugular intrahepatic portosystemic shunt creation (white arrow) between the middle hepatic vein (HV) and the right portal vein (PV). C) During the second procedure, a balloon occlusion portal venography was performed after the deployment of a flow restrictor stent (black asterisk). There was an $8 \mathrm{mmHg}$ portal pressure increase to $14 \mathrm{mmHg}$. D) As portal pressure remained low, the TIPS was ultimately closed using a vascular plug (white asterisk)

CEPS remained occluded, liver nodules size decreased, the patient is asymptomatic and did not develop additional complications. Total bilirubin $(68,4 \mu \mathrm{mol} / \mathrm{L})$, alanine transaminase $(68 \mathrm{IU} / \mathrm{L})$ and aspartate transaminase (39 IU/L) did not decrease to normal levels.

\section{Discussion}

The literature on endovascular multistage closure of type II CEPS is scarce. For longer length shunts custommade flow restrictors (Bruckheimer et al., 2013; Roggen et al., 2018) and consecutive intra shunt stent deployment and epithelization (Eroglu et al., 2004) have been utilized. However, to our knowledge, only one case of a shorth length multistage closure has been reported, which combined an IVC stent with a temporary TIPS (Chick et al., 2017).

Herein we report a novel technique with the combinations of an atrial septal defect occluder with a temporary TIPS. The off-label usage of atrial septal defect occluders have been previously reported in single stage occlusions of short length CEPS (Alharbi et al., 2017; Kuo et al., 2010). They have a reduced risk of migration, with larger outer disks in the portal vein and vena cava acting as a lock mechanism, and a reduced risk of turbulent flow due to their relatively low thickness. As for the TIPS, it both decreases the shunted portal blood, as a result of 
its smaller diameter in relation to the CEPS, and acts as a conduit for further embolization. In multistage closure measuring the portal pressure during shunt balloon occlusion is critical not only in the initial evaluation but also between procedures, as it dictates whether a partial or a definitive occlusion is indicated.

Regarding patient follow up the hepatic nodules size decreased and no further complications developed. This is consistent with the literature in which shunt closure is effective in both management and prevention of complications, particularly important considering the risk of developing fatal complications such as pulmonary hypertension and hepatocellular carcinoma (Baiges et al., 2020).

\section{Conclusion}

This report highlights the feasibility of endovascular closure in complex CEPS, supporting its usage as an alternative to the standard surgical treatment. However, since it's a single case report, further studies are necessary to validate its efficiency and safety.

\section{Abbreviations}

CEPS: Congenital extrahepatic portosystemic shunt; IVC: Inferior vena cava; TIPS: Transjugular intrahepatic portosystemic shunt

\section{Acknowledgments}

Not applicable.

\section{Authors' contributions}

PD and AA performed the procedure. JF drafted the manuscript with substantial contributions of the remaining authors. All authors read, reviewed, and approved the final manuscript.

\section{Funding}

This study was not supported by any funding.

Availability of data and materials

Not applicable.

\section{Declarations}

Ethical approval

For this type of study, formal consent is not required.

Informed consent

For this type of study, informed consent is not required.

\section{Consent for publication}

Written informed consent was obtained from the patient for publication of this case report.

\section{Competing interests}

The authors declare that they have no conflict of interest.

\section{Author details}

'Medical Imaging Department, Coimbra University Hospital, Praceta Prof. Mota Pinto, Coimbra, Portugal. ${ }^{2}$ Faculty of Medicine of the University of Coimbra, Azinhaga de Santa Comba, Coimbra, Portugal.

Received: 29 July 2021 Accepted: 8 November 2021

Published online: 18 November 2021

\section{References}

Alharbi A, Abdulrahman S, AlOtaibi M, Alomrani A, Arabi M (2017) Congenital extrahepatic portosystemic shunt embolization with the use of a duct
Occluder in a neonate with liver dysfunction and Hyperammonemia. J Vasc Interv Radiol 28(9):1291-1293. https://doi.org/10.1016/.jvir.2017.05.016

Alonso-Gamarra E, Parrón M, Pérez A, Prieto C, Hierro L, López-Santamaría M (2011) Clinical and radiologic manifestations of congenital extrahepatic portosystemic shunts: a comprehensive review. Radiographics 31(3):707-723. https://doi.org/10.1148/rg.313105070

Baiges A, Turon F, Simón-Talero M, Tasayco S, Bueno J, Zekrini K, Plessier A, Franchi-Abella S, Guerin F, Mukund A, Eapen CE, Goel A, Shyamkumar NK, Coenen S, De Gottardi A, Majumdar A, Onali S, Shukla A, Carrilho FJ et al (2020) Congenital extrahepatic portosystemic shunts (Abernethy malformation): an international observational study. Hepatology 71(2):658669. https://doi.org/10.1002/hep.30817

Bruckheimer E, Dagan T, Atar E, Schwartz M, Kachko L, Superina R, Amir G, Shapiro R, Birk E (2013) Staged transcatheter treatment of portal hypoplasia and congenital portosystemic shunts in children. Cardiovasc Intervent Radiol 36(6):1580-1585. https://doi.org/10.1007/s00270-013-0581-7

Chick JFB, Reddy SN, Yu AC, Kelil T, Srinivasa RN, Cooper KJ, Saad WE (2017) Three-dimensional printing facilitates successful endovascular closure of a type II Abernethy malformation using an Amplatzer atrial septal Occluder device. Ann Vasc Surg 43(311):e15-311.e23. https://doi.org/10.1016/j.avsg.201 7.02 .012

Eroglu Y, Donaldson J, Sorensen LG, Vogelzang RL, Melin-Aldana H, Andersen J, Whitington PF (2004) Improved neurocognitive function after radiologic closure of congenital portosystemic shunts. J Pediatr Gastroenterol Nutr 39(4):410-417. https://doi.org/10.1097/00005176-200410000-00019

Franchi-Abella S, Gonzales E, Ackermann O, Branchereau S, Pariente D, Guérin F (2018) Congenital portosystemic shunts: diagnosis and treatment. Abdom Radiol 43(8):2023-2036. https://doi.org/10.1007/s00261-018-1619-8

Kuo MD, Miller FJ, Lavine JE, Peterson M, Finch M (2010) Exploiting phenotypic plasticity for the treatment of Hepatopulmonary shunting in Abernethy malformation. J Vasc Interv Radiol 21(6):917-922. https://doi.org/10.1016/j. jvir.2010.01.038

Rajeswaran S, Johnston A, Green J, Riaz A, Thornburg B, Mouli S, Lautz T, Lemoine C, Superina R, Donaldson J (2020) Abernethy malformations: evaluation and management of congenital portosystemic shunts. J Vasc Interv Radiol 31(5):788-794. https://doi.org/10.1016/j.jvir.2019.08.007

Roggen M, Cools B, Maleux G, Gewillig M (2018) A custom-made percutaneous flow-restrictor to manage a symptomatic congenital Porto-systemic shunt in an infant. Catheter Cardiovasc Interv 92(1):92-95. https://doi.org/10.1002/ ccd. 27634

\section{Publisher's Note}

Springer Nature remains neutral with regard to jurisdictional claims in published maps and institutional affiliations.

\section{Submit your manuscript to a SpringerOpen ${ }^{\circ}$ journal and benefit from:}

- Convenient online submission

- Rigorous peer review

- Open access: articles freely available online

- High visibility within the field

- Retaining the copyright to your article

Submit your next manuscript at $\boldsymbol{\nabla}$ springeropen.com 